\title{
Sustainable Tourism in the Metropolitan Area
}

\author{
Francesco Saverio Nesci ${ }^{1, a}$ \\ ${ }^{1}$ Mediterranea University of Reggio Calabria \\ Department of Agricultural Sciences - Località Feo di Vito - 89124 Reggio Calabria - Italy \\ afrancesco.nesci@unirc.it
}

Keywords: Sustainable Tourism, Typical Products, Knowledge and Tastes.

\begin{abstract}
The tourism market, as any other economic sector, demands organisation and competition. As a consequence, integrated strategies are necessary in order to improve and qualify the supply, in terms of receptivity, resource usability, additional services and marketing. The impending metropolitan area, for its intrinsic features, could play a double role in the tourism sector as both destination and hub for the whole regional territory, as it is rich in natural resources although simultaneously lacking in services. A correct valorization of these territories needs a targeted tourism focused on blending "knowledge", connected to history, and "taste", as testified by the rural tradition.

The territory needs to be seen as a product to be sold, complying to the rules of territorial marketing, supporting best practice experiences as "Le reggine dei Sapori" a territorial brand created to maximize agro-food products, and "Strada dei vini e dei sapori della Locride", that turned the territory into a system that hands down the knowledge and tradition of "Magna Graecia" and its typical products, in the perspective that "Sustainable development is development that meets the needs of the present without compromising the ability of future generations to meet their own needs".
\end{abstract}

\section{Presentation}

Calabria is a land of myths and legends, a crib of ancient civilizations where the origins and the spread of many century-old cultures were developed. Thanks to the presence and willingness of its inhabitants and to their capacity to improve, transform and preserve their culture, this heritage has become a natural patrimony, being an interesting basis for a productive integrated system intended for tourism.

Thinking Calabria, we usually ascribe its underdevelopment to a rugged orography, to a strongly atomized company profile, and to a general underdevelopment of southern Italy, as epitomized by the "Southern Question" developed after the Unification of Italy, and to the disposition of individuals, shaped by the different governments coming in succession over the centuries. It is featured by a sort of "fatalism" typical of Arab populations and by the objective and subjective difficulties linked to business and network creation. This mentality, so entrenched in the past generations, also results from the failure of the industrial miracle that led to the neglect of an appropriate evaluation of natural resources for tourism purposes, along with the primary sector.

The tourism market, however, as any other economic sector, demands organisation and competition. As a consequence, integrated strategies are necessary in order to improve and qualify the supply, in terms of receptivity, resource usability, additional services and marketing; it is especially true if seen in the perspective of an appropriate development of the metropolitan city, as provided by L. 142/90 (art. 17-21) on reform of local authorities [1].

\section{The metropolitan area of Reggio Calabria}

The metropolitan area of Reggio Calabria results from the conurbation of the administrative center and 21 other municipalities located along the coasts of Reggio on the Straits of Messina. These urban centres are featured by a strong social and economic interaction and they develop over an area of about $850 \mathrm{~km} 2$, with a population of about 270.000 inhabitants. 
Table 1. The metropolitan area of Reggio Calabria with 21 municipalities [1]

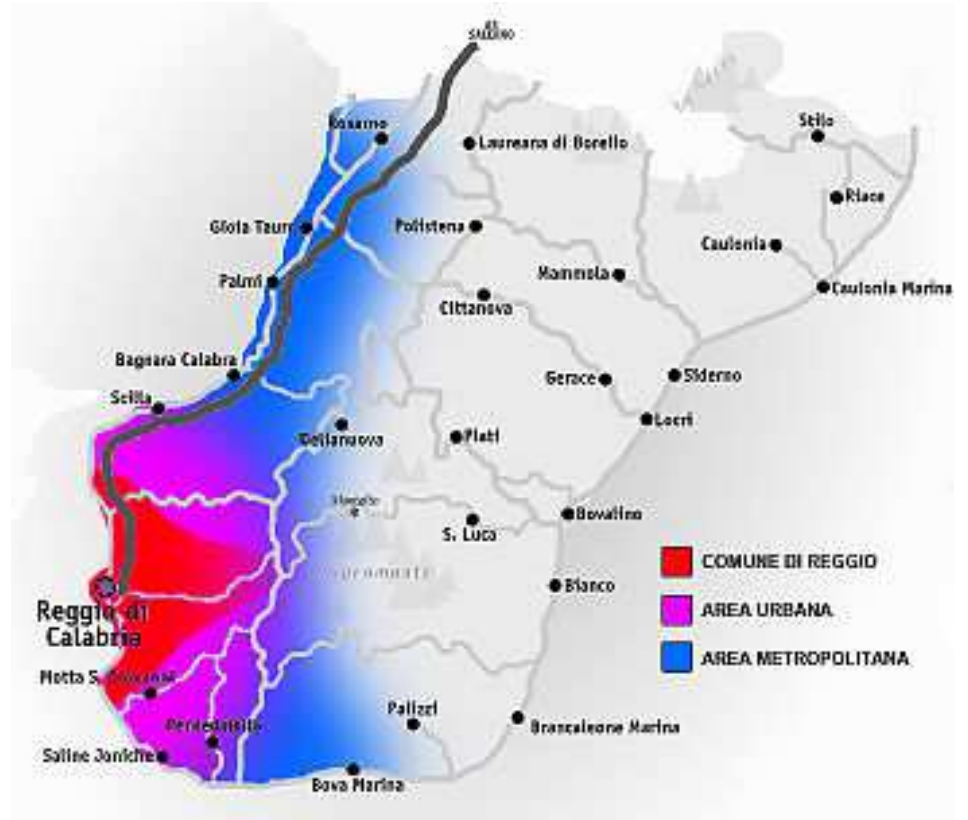

In recent years, the thesis suggesting that the metropolitan area should match the whole provincial territory has been supported; according to it, 97 municipalities would be involved, covering an area of $3.183 \mathrm{~km} 2$ and 550.000 inhabitants, as provided by the Acts that are currently being discussed by the parliament.

As a fact, the city of Reggio Calabria is located in the exact centre of a wide metropolitan area featured by a territorial, cultural, social and economic continuity with Messina, which would be part of the Integrated Metropolitan area, with 900.000 inhabitants.

Rosen up on the remains of an important and flourishing colony of Magna Graecia, Reggio has a modern urban asset, resulting from the catastrophic earthquake of 1908. Having the natural amphitheatre of Aspromonte mountains on its background, the city represents one of the main regional hubs in terms of economy and services; it is the place where transports connections and assets meet and it is a natural point of reference in logistics, due to its strategic position within the Mediterranean Area.

The impending metropolitan area, for its intrinsic features, could play a double role in the tourism sector as both destination and hub for the whole regional territory, as it is rich in natural and cultural resources (which is also confirmed by cultural events like country festivals where the sacred and the profane meet) although simultaneously lacking in services [2].

\section{The lack of services}

Concerning services, waste management is one of the issues demanding a new productive and dynamic perspective. It would make it possible to turn problems into opportunities by setting a complete and autonomous system into place which would enable an efficient separate collection of rubbish. It would emphasize all those components that could become "secondary raw materials", facilitating their employment in the local productive system.

It is necessary to focus on reducing the quantity of waste to be processed in stations for garbage disposal, which clearly represent an environmental issue, and on the related costs, creating new productive activities that impact employment and, especially, the image of this land.

A similar analysis can be done with reference to an appropriate processing of farming waste, which is potentially useful if destined to biomass and electric power production. 
Concerning purification, in the province of Reggio Calabria only $48,2 \%$ of the population enjoy an efficient service (at least a secondary processing), which is a lower data compared to the regional average of $49,9 \%$, and much lower than the national average of $76 \%$, being definitely below the southern Italian average of $66 \%$. This critical situation is connected to water pollution due to a lack of management of the purification stations, to the presence of unauthorized drains and to an overall general condition of decay.

City transport results as inadequate as waste management in terms of both incoming and metropolitan services. Its peripheral position is made worse by a poor street network and lack of services, while the presence of the airport and the harbour connecting Sicily is not fully taken advantage of as it should be. The harbour of Gioia Tauro, with its focal position in the Mediterranean, was built for the service of the steel factory in the 1970s. Since the factory was closed down due to the sector crisis, the harbour has become the main terminal for transshipment and a useful departure gate for agro-food products coming from the whole area.

According to a reported underutilization of the exhisting accommodation facilities, as highlighted by an employment low average rate, it is thus necessary to plan strategies for the structural development of the tourist chain and, along with it, of the whole territory; moreover, it is essential to activate a network of institutional actors and trade associations, in order to put the territory characteristics, material and immaterial resources together reliably available to the tourist.

\section{Strategies for sustainable tourism}

It is therefore necessary to set new and more effective strategies for sustainable tourism; focus must be on the valorisation of the land identity aiming at making the destination more competitive. It means excellent services, enticing attractions that depends less on seasons, the capacity to fulfill new requests and authentic experiences with low environmental impact.

Combining farming and tourism could represent the keystone to emphasize the realities that keep our productive system alive. These are precious to preserve tradition and products for which "interstice opportunities" are still possible.

What makes a product typical is its link with the territory it belongs to, as customers experience it as a strongly reassuring element. In an economic and company perspective, typical products can be considered "specialty goods" for their unique characteristics, or cultural goods, as they have deep symbolic and communicative connotations. These products are therefore entitled to represent the territory outside its own borders. For the customer, they can fulfill different expectations becoming a multidimensional entity; in fact, they have a functional value, as they fulfill a primary need, together with a social value, when connected to a specific social group, and an emotional one, when able to awaken feeling and affection. When purchasing a typical product, the customer not only enjoys qualitative excellence, but he can also take part in cultural and geographic traditions, in a social and cultural specific context, as those products represent "the outcome of an historical collective and local process of accumulation of contextual knowledge founded on a combination of specific territorial resources, both physical and anthropic, that give birth to a strong, unique and irreproducible bond with the area of origin" [3].

In other words a "typical" product is "an economic supply provided by one or more companies situated in a territory that is geographically, culturally and historically connoted, being it perceived as a unique product made of a mix of tangible and intangible elements and featured by a distinctive image or identity". The mentioned products are thus made by traditional processes employing specific local resources where their specific characteristics, partially or completely, come from. To sum up, it is possible to make reference to some specific dimensions that make typical product characteristics of their country and they are the peculiarity of local resources, both natural and human, history, local cultural identity and a collective dimension [3].

Local resources can be seen as distinct of a country as they are related to the physical and climatic characteristics of that country, and to the human resources responsible for emphasizing those characteristics. History, local tradition and cultural identity all bring the necessary knowledge to keep and adjust typical products and to strengthen their bond with the local population, making 
them become part of the territory identity, resulting from productive, natural and cultural resources that are part of that same territory. The ties between the product and the community it comes from is also determinant. In fact, the product gives body to an old knowledge shared by a local community. Typical products can also have an existence value, connected to local features but going beyond them. As a consequence, the characteristics cannot easily be defined, as it depends on different levels of connection to the territory in terms of both quality and quantity, although an element remains constant and this is the bond itself with the territory.

The valorization of wide areas of the territory can therefore be incentivized connecting "knowledge", descending from local tradition and influences from the past, and "tastes" of typical products, as testified by a rural "niche" tradition [4].

"Wine and food" tourism can therefore represent a way to emphasize the territory when we think of it as "the outcome of an historical collective and local process of accumulation of contextual knowledge founded on a combination of specific territorial resources, both physical and anthropic, that give birth to a strong, unique and irreproducible bond with the area of origin" [3].

A typical product is an "economic supply provided by one or more companies situated in a territory that is geographically, culturally and historically connoted, being it perceived as a unique product made of a mix of tangible and intangible elements and featured by a distinctive image or identity" [3].

The province of Reggio Calabria is featured by its exclusive production of POD bergamot, a green and multifunctional product famous for its essence and that all its components can be used. Olive farming is extremely important as it covers the Plains of Gioia Tauro almost completely; this area is by many considered a "museum" of olive farming for the size and beauty of its trees. Two wines are POD certified, Bivongi and Greco di Bianco, whereas six wines are IGT certified: Arghilla, Costa Viola, Locride, Mantonico di Bianco, Palizzi, Pellaro and Scilla [4].

Many other wines produced in small villages have atypical characteristics as they belong to a local and artisan dimension; they are usually made with traditional and empiric methodologies and they are commonly intended for a historically poor kitchen, featured by strong flavors, as already recounted by Norman Douglas in "Old Calabria", a travel journal from the early 1900.

In this context, the territory needs to be seen as a product to be sold, with its history and typical and/or traditional products, complying to the rules of territorial marketing, supporting best practice experiences as "Le reggine dei Sapori" a territorial brand created to maximise products coming from the province of Reggio Calabria, conceived by the Provincial Department for Economic Development in order to put small companies together and represent the best productions of the gastronomic sector of the Calabrian 'finis terrae'.

This experience, together with the connected marketing tool, aims at fostering a policy intended to support niche products together with tourism development, by creating and advertising quality "wine and food" routes. Another example can be identified in the "Strada dei Vini e dei Sapori della Locride", that turned the territory into a system that hands down the knowledge and tradition of "Magna Graecia" and its typical products. In a similar perspective, it will not be seen as a simple geographic route anymore, but as a network of entities willing to join and cooperate in order to promote, market and sell the territory itself as a product, together with its culture and experience of a possible way of life.

The name originates from the decision to include "wine and food" supply to the essential association made up of wine and typical products. Although the area of Locri cannot rely on such quantities as to guarantee economic sustainability to a development intervention exclusively aimed at wine, it can count on a wide variety of typical products that could offer the right support to an integrated "wine and food" supply.

\section{Conclusions}

A similar form of tourism is well connected to the concept of supply sustainability, which is the presence of tourist structures and services that will not hinder landscape, sea and environment and that will help correct fruition of the backcountry, rich in history and uncontaminated nature. 
In this perspective, it seems appropriate to mention the more general definition of sustainable tourism as stated by WCED (World Commission on Environment and Development) in the Brundtland Report of 1987: "Sustainable development is development that meets the needs of the present without compromising the ability of future generations to meet their own needs".

\section{References}

[1] Information on http://www.wikipedia.org/

[2] Camera di Commercio Reggio Calabria - Rapporto sull'economia provinciale - Annate varie.

[3] G. Giordano: Produzioni di qualità e valorizzazione del territorio nel mercato dei prodotti agroalimentari tipici all'interno del mercato globale. Tesi di laurea. Corso di laurea in Scienze Economiche. Facoltà di Giurisprudenza. Università degli studi Mediterranea di Reggio Calabria. A.A.2012-2013

[4] F.S. Nesci, N. Sapone: Il settore agroalimentare in Calabria : situazione attuale e prospettive. XLIII Convegno CESET : Sviluppo economico e nuovi rapporti tra agricoltura, territorio ed ambiente. Verona, (2013) 